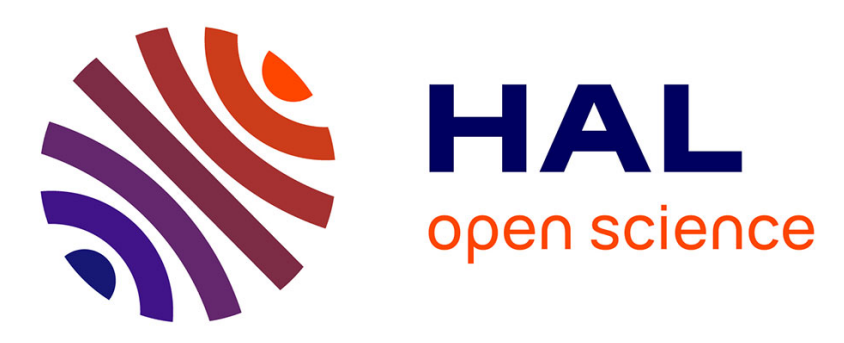

\title{
Design and self-assembly of PBLG-b-ELP hybrid diblock copolymers based on synthetic and elastin-like polypeptides
}

Gaëlle Le Fer, Delphine Portes, Guillaume Goudounet, Jean-Michel Guigner, Elisabeth Garanger, Sébastien Lecommandoux

\section{To cite this version:}

Gaëlle Le Fer, Delphine Portes, Guillaume Goudounet, Jean-Michel Guigner, Elisabeth Garanger, et al.. Design and self-assembly of PBLG-b-ELP hybrid diblock copolymers based on synthetic and elastin-like polypeptides. Organic \& Biomolecular Chemistry, 2017, 15 (47), pp.10095-10104. 10.1039/C7OB01945A . hal-01660141

\section{HAL Id: hal-01660141 https://hal.science/hal-01660141}

Submitted on 8 Jul 2019

HAL is a multi-disciplinary open access archive for the deposit and dissemination of scientific research documents, whether they are published or not. The documents may come from teaching and research institutions in France or abroad, or from public or private research centers.
L'archive ouverte pluridisciplinaire HAL, est destinée au dépôt et à la diffusion de documents scientifiques de niveau recherche, publiés ou non, émanant des établissements d'enseignement et de recherche français ou étrangers, des laboratoires publics ou privés. 
Author manuscript of Org. Biomol. Chem., 2017,15, 10095-10104 DOI: 10.1039/C7OB01945A

\section{Design and self-assembly of PBLG-b-ELP hybrid diblock copolymers based on synthetic and elastin-like polypeptides}

Gaëlle Le Fer ${ }^{\S \dagger}$, Delphine Portes ${ }^{\S \dagger}$, Guillaume Goudounet ${ }^{\S \dagger}$, Jean-Michel Guigner ${ }^{\ddagger}$, Elisabeth Garanger $^{\S \dagger^{* *}}$, Sébastien Lecommandoux ${ }^{\S \dagger^{* *}}$

$\S$ Université de Bordeaux/Bordeaux INP, ENSCBP, 16 avenue Pey-Berland, Pessac 33607, France

$\dagger$ CNRS, Laboratoire de Chimie des Polymères Organiques (UMR5629), Pessac, France

¥Institut de Minéralogie et de Physique des Milieux Condensés (IMPMC) 4 place Jussieu -75005 Paris - France

*Correspondence to: Sébastien Lecommandoux (E-mail: lecommandoux@enscbp.fr); Elisabeth Garanger (E-mail: garanger@enscbp.fr)

Key-words: Elastin-like polypeptides, poly( $\gamma$-benzyl- $L$-glutamate), amphiphilic block copolymers, microfluidics, self-assembly. 
Author manuscript of Org. Biomol. Chem., 2017,15, 10095-10104 DOI: 10.1039/C7OB01945A

\begin{abstract}
The precision synthesis and self-assembly of amphiphilic copolypeptides containing a recombinant elastin-like polypeptide (ELP) block used as macroinitiator for the ring opening polymerization (ROP) of $\gamma$-benzyl-L-glutamate $(\gamma$-BLG NCA) are herein presented. The molecular weight of the resulting PBLG- $b$-ELP block copolypeptides was precisely controlled without the use of complex initiators or demanding experimental setup. Diblock copolypeptides were obtained with an excellent control of the polymerization highlighted by the dispersity below 1.04. These amphiphilic hybrid synthetic/recombinant copolypeptides were self-assembled in water and nanoparticles obtained characterized by a combination of dynamic light scattering and electron microscopy. A variety of morphologies, namely polymersomes, inter-connected wormlike micelles and spherical micelles, were evidenced depending on the hydrophilic ratio of the diblocks as well as the self-assembly procedure.
\end{abstract}

\title{
Introduction
}

Over the past decades, several approaches have been developed for the elaboration of block copolymer systems based on proteins for various applications. For instance, therapeutic proteins can replace deficient or absent natural proteins, upregulate existing metabolic pathways, their conjugation with hydrophilic polymer being at the origin of important research area and biotechnology development. Upon them, poly(ethylene glycol) (PEG) is the most intensively used polymer for bioconjugation, allowing longer half-life in the bloodstream, and leading to less frequent dosing. ${ }^{1}$ In addition, giant amphiphiles, copolymers resulting from the controlled conjugation of synthetic polymers to proteins $^{2}$ can be interestingly used for their self-assembly 
Author manuscript of Org. Biomol. Chem., 2017,15, 10095-10104 DOI: 10.1039/C7OB01945A

behavior. In this context, the perfect control of the chemical structure and bioconjugation mechanism is a prerequisite. In pioneered work in this area, Nolte et al. studied the self-assembly of precisely defined giant amphiphiles consisting of a single hydrophobic polystyrene tail covalently connected to a lipase $\mathrm{e}^{3}$ and via cofactor reconstitution to horseradish peroxidase (HRP) or myoglobin. ${ }^{4,5}$ Velonia and co-workers showed the potential of hydrids BSA-polystyene to create bionanoreactors, ${ }^{6}$ and the self-assembly behavior of tri-block giant amphiphilic BSAcopolymer synthesized by a combination of Atom Transfer Radical Polymerization (ATRP) and "click chemistry". Thereafter, Bulmus et al. developed thermoresponsive BSA-poly(Nisopropylacrylamide) via the growth of the polymer chains from BSA-macroRAFT (Reversible Addition Fragmentation Chain Transfer) agent. ${ }^{8}$ More recently, vesicles were obtained from the self-assembly of BSA-poly(caprolactone) ${ }^{9}$ or HSA-poly(N-(2-hydroxypropyl) methacrylamide $)^{10}$ and demonstrated great potential as drug-nanocarriers, taking advantage of the stealth character of BSA as the hydrophilic segment. In most recent example, Mann et al. ${ }^{11}$ used such conjugates to built stimuli-responsive biomimetic protocells using BSA-PNIPAM based copolymers.

In the past decade, the library of proteins was significantly extended, and recombinant proteinengineering techniques allowed the development of precision recombinant polymers with exquisite control over their primary structure. Among them, elastin-like polypeptides (ELPs) represent a unique class of recombinant proteins. Their main structure results in repeating sequences of [-Val-Pro-Gly-Xaa-Gly-] pentapeptides, the guest residue Xaa being any amino acid except proline. ELPs share structural characteristics with intrinsically disordered proteins naturally found in the body, such as tropoelastin, at the origin of their name. ${ }^{12,13}$ The repeat sequences found in the biopolymer, as well as the monomer sequence an chain length, give each ELP a distinct structure, and influence the lower critical solution temperature (LCST), also 
Author manuscript of Org. Biomol. Chem., 2017,15, 10095-10104 DOI: 10.1039/C7OB01945A

referred to commonly as the $T_{t}$. Recent contributions highlighted the tunable thermoresponsive properties of ELPs in water by chemoselective oxidation ${ }^{14}$ or alkylation ${ }^{15,16}$ of all methionine residues, with the aim of providing polycationic derivatives in the later case or introducing new side-chain functionalities.

In this context, ELPs may find an original place as protein block in hybrid protein-polymer bioconjugates. Indeed, the elaboration of synthetic polymers-ELPs conjugates were reported, such as low molecular weight ELP-based side chain poly(methacrylate)s via ATRP ${ }^{17,18}$ and ELPgrafted poly(norbornene)s via ring-opening metathesis polymerization (ROMP) ${ }^{19,20}$ in presence of catalyst based on ruthenium. Moreover, ELPs obtained by chemical pathway (Boc-based liquid phase synthesis) were conjugated with polyamidoamine (PAMAM) dendrimers to gain potential stimuli-responsive drug-carrier. ${ }^{21}$ More recently, Kiick and co-worker ${ }^{22}$ reported the self-assembly behavior in vesicles of elastin- $b$-collagen-like peptide bioconjugates obtained by copper(I)-catalyzed alkyne-azide cycloaddition (CuAAC) "click" reaction.

Although peptide-polymer and protein-polymer conjugates were studied, conjugates of hybrid protein-synthetic polypeptide are surprisingly less explored whereas the polymerization of $\mathrm{N}$ carboxyanhydrides (NCAs) allows obtaining well-defined macromolecular structures, even from a macro-initiator. Indeed, block copolymer are usually prepared by using the first block with an amino end-group as a macroinitiator for the ring opening polymerization (ROP) of NCAs, this block being often $\mathrm{PEG},{ }^{23-26}$ even if some other example referred to poly[N-(2-hydroxypropyl) methacrylamide] (PHPMA) of high molecular weight $\left(\overline{M_{n}}=32,100\right.$ g.mol $\left.{ }^{-1}\right) .{ }^{27}$

The NCAs ROP can proceed via 2 mechanisms: the normal amine mechanism (NAM, induced by nucleophilic substitution) proposed by Waley and Watson $^{28}$ and the activated monomer 
Author manuscript of Org. Biomol. Chem., 2017,15, 10095-10104 DOI: 10.1039/C7OB01945A

mechanism (AMM, induced by deprotonation of the NCAs). ${ }^{29}$ AMM yields polypeptides with high molar mass and broad dispersity. As a result, the NAM mechanism must be favored to obtain well-defined polypeptides. Most commonly, nucleophiles are used to initiates the polymerization, with primary amines being the most intensively investigated species. In addition to the versatility of synthesis and the intrinsic biodegradability of peptide bonds, the supramolecular organization of polypeptides provides an opportunity to produce hierarchical structures and can also be used to promote specific "bioactivity". 30-32 For instance, block copolymers combining polypeptide and oligosaccharide blocks have previously been employed to prepare glycoprotein biomimetic polymersomes. ${ }^{33-35}$

The goal of the present contribution is to combine the various advantages of ELPs and synthetic polypeptides to obtain a "hybrid" amphiphilic diblock recombinant/synthetic polypeptide capable of self-assembly in various biocompatible nano-structures. In this context, this article highlights the use of hydrophilic ELP as a macroinitiator for the ROP of $\gamma$-BLG-NCA. The diblock polypeptides were obtained with a high control of the polymerization mechanism, highlighted by the low dispersity of the resulting copolymers, below 1.04. The resulting amphiphilic hybrid diblocks were subsequently self-assembled, using a microfluidic chip system and more "classical" methods such as dialysis or direct dissolution. The goal of our study is to establish structure-property relationships between the weight fraction of each block and the size and morphology of the resulting nano-objects depending on the self-assembly process used. 
Author manuscript of Org. Biomol. Chem., 2017,15, 10095-10104 DOI: 10.1039/C7OB01945A

\section{Results and discussion}

Synthesis of PBLG-b-ELP block copolypeptides

The most rapid and cost-effective process to prepare synthetic polypeptide chains with high degrees of polymerization and excellent control over the dispersity is the ROP of heterocycle $\alpha$ amino acid $N$-carboxyanhydrides (NCAs). ${ }^{36-38}$ Poly $(\gamma$-benzyl- $L$-glutamate)-block-ELP (PBLG- $b$ ELP) copolypeptides studied in this work were therefore prepared in high efficacy and with high purity by ROP of $\gamma$-BLG NCA using the $N$-terminal group of the ELP as initiating group. A series of hybrid copolypeptides with different PBLG block lengths was synthesized in order to study the influence of this parameter, among others, on their self-assembly behavior.

The ELP used in this work was recombinantly produced in Escherichia coli using protein engineering techniques as described previously. ${ }^{14}$ This ELP contains a total of forty pentapeptide repeats according to the protein sequence $\mathrm{MW}\left[(\mathrm{VPGVG})(\mathrm{VPGMG})(\mathrm{VPGVG})_{2}\right]_{10}$ corresponding to a molecular weight of $17,035 \mathrm{Da}$. From the ELP primary structure, the only functional group able to initiate the polymerization is indeed the primary amine present on the $N$-terminal group. The ${ }^{1} \mathrm{H}$ NMR spectrum in $\mathrm{CDCl}_{3}$ with $15 \%$ of trifluoroacetic acid (TFA, to compare with spectrum after polymerization) of the ELP (Figure S1) was recorded and all peaks fully assigned for subsequent comparison with PBLG- $b$-ELP ${ }^{1} \mathrm{H}$ NMR spectra. The peak at $0.94 \mathrm{ppm}$ attributed to the resonance of the $\mathrm{CH}_{3}$ of the 70 valine residues $\left(420{ }^{1} \mathrm{H}\right.$ total $)$ was used for the calibration.

The ELP was subsequently used as macroinitiator for the ROP of $\gamma$-BLG NCA. Firstly, the polymerizations were initially performed in anhydrous DMF at $25^{\circ} \mathrm{C}$ for 24 hours. Pure products were isolated by precipitation in diethyl ether. The degree of polymerization (DP) of each compound was determined by ${ }^{1} \mathrm{H}$ NMR in $\mathrm{CDCl}_{3}$ containing $15 \%$ of TFA. The DP was 
Author manuscript of Org. Biomol. Chem., 2017,15, 10095-10104 DOI: 10.1039/C7OB01945A

calculated by comparing the integral of the peak at $5.10 \mathrm{ppm}$ corresponding to the resonance of the methylene group in $\alpha$ of the benzyl ring $\left(2{ }^{1} \mathrm{H}\right.$ per BLG unit) to the integral of the peak at 0.94 ppm used for calibration (vide supra, $420{ }^{1} \mathrm{H}$ ). Four PBLG-b-ELP copolypeptides were obtained with DP ranging from 21 to 110. Because the experimental DP in each case was far below the targeted DP (Table S1, e.g. a DP 21 was obtained when DP 52 was targeted), we concluded that the polymerizations stopped before total consumption of the monomer. The increased polydispersity index $Ð$ of PBLG- $b$-ELP copolypeptides with DP above 61 (Table S1) attributed to the presence of a shoulder in the size exclusion chromatography (SEC) profiles (Figure 3a) also suggested the uncontrolled character of the polymerization under these conditions. Indeed, it was previously reported that side reactions, such as chain-end terminations and the formation of formyl end-groups can occur at $25{ }^{\circ} \mathrm{C}$ during the polymerization of NCAs. ${ }^{39}$ More precisely, regarding the synthesis of PBLG, Hanby and co-workers ${ }^{40}$ described in the 50 's, the polypeptide chain termination, where the amine chain-end reacts with the carbonyl of the last unit side chain to form a stable 5-atoms heterocycle (i.e., pyrrolidone). When occurring during polymerization, this reaction leads to the termination of the growing chain and is responsible for the poor control of the polymerization. ${ }^{36,39}$ To avoid this problem that is specific to the ROP of $\gamma$-BLG NCA, the polymerization reactions were performed in anhydrous DMF at low temperature $\left(5^{\circ} \mathrm{C}\right)(\mathrm{Scheme}$ 1). Indeed, it was previously demonstrated that low reaction temperatures reduce the frequency of this premature termination since this reaction requires a higher activation energy. ${ }^{39,41-43}$

Under these conditions, all $N$-terminal groups of ELP chains initiated the ROP as evidenced by the excellent yields. (Table 1) Complete conversions were achieved according to the excellent agreement between theoretical and experimental DPs as assessed by ${ }^{1} \mathrm{H}$ NMR and targeted DPs (Figure 1). Four PBLG- $b$-ELP copolypeptides with DP ranging from 25 to 180 were obtained, 
Author manuscript of Org. Biomol. Chem., 2017,15, 10095-10104 DOI: 10.1039/C7OB01945A

corresponding to PBLG blocks between 5,500 and 39,500 g. $\mathrm{mol}^{-1}$ molecular weights and diblock PBLG- $b$-ELP copolypeptides between 22,500 and 56,500 g.mol ${ }^{-1}$ molecular weights, respectively. All hybrid copolypeptides were characterized by SEC in DMF $\left(0.8 \mathrm{~mL} \cdot \mathrm{min}^{-1}\right)$ at 50 ${ }^{\circ} \mathrm{C}$ in the presence of $\operatorname{LiBr}\left(1 \mathrm{~g} . \mathrm{L}^{-1}\right)$ with RI detector and polystyrene used as standard. Using this setup, the apparent molar mass of the ELP was 18,000 g.mol ${ }^{-1}$, while diblock copolypeptides' apparent molar masses were comprised between 33,300 and 56,200 g.mol ${ }^{-1}$. Values estimated by SEC were found in relatively good adequacy with the values obtained by ${ }^{1} \mathrm{H}$ NMR. (Table 1) The SEC chromatograms evidenced monomodal distributions of polypeptide chains with narrow dispersities (1.02 - 1.03) indicating the well-controlled character of the polymerization. (Table 1 and Figure 2b) Consequently the presence of the carboxylic group at the $C$-terminal end of the ELP did not appear to be disadvantageous in the polymerization. Aoi and co-workers actually showed that the presence of a nucleophilic carboxylate provides control over the polymerization of sarcosine-NCA. ${ }^{44}$

To summarize the synthetic part of this work, the ROP of $\gamma$-NCA BLG initiated by a high molecular weight recombinant ELP was conducted at $5{ }^{\circ} \mathrm{C}$ to prevent chain termination reactions during the polymerization. A total of four, well-defined, hybrid diblock copolymers associating a synthetic hydrophobic polypeptide block and a biocompatible elastin-like polypeptide block were obtained. These differ by the length of the hydrophobic PBLG block and therefore feature different hydrophilic weight fractions $(f)-\mathrm{PBLG}_{25}-b$-ELP $(f=76 \%), \mathrm{PBLG}_{45}-b$-ELP $(f=63 \%)$, $\mathrm{PBLG}_{95}-b$-ELP $(f=45 \%)$ and $\mathrm{PBLG}_{180}-b$-ELP $(f=30 \%)$ - a critical parameter that influences amphiphilic copolypeptide self-assembly. ${ }^{45-47}$

Self-assembly of PBLG-b-ELP block copolypeptides 
Author manuscript of Org. Biomol. Chem., 2017,15, 10095-10104 DOI: 10.1039/C7OB01945A

The self-assembly in water of the different PBLG- $b$-ELP copolypeptides was performed using different methodologies, more precisely dialysis or microfluidics and direct solubilization in the case of $\mathrm{PBLG}_{25}-b$-ELP with the highest hydrophilic weight fraction $(f=76 \%)$. These methods were selected among others to obtain stable nanoparticles of controlled size and morphologies under kinetic or thermodynamic control. Temperature of the solutions during the self-assembly process and the dialysis was carefully maintained at $20^{\circ} \mathrm{C}$ to overcome the impact of this parameter. The self-assembly studies were performed at the concentration of 4 g. $\mathrm{L}^{-1}$, namely the highest polypeptide concentration avoiding the formation of macroscopic aggregates in the dialysis tubing or in the microfluidic chip. Concentrations lower than 2 g. $\mathrm{L}^{-1}$ resulted in the formation of similar nanostructures that were however difficult to characterize because of the high dilution after dialysis. The resulting self-assemblies were characterized by transmission electron microscopy (TEM) (Figures 3 and S2a) and dynamic light scattering at $90^{\circ}$ (DLS) (Figures S2b and S3).

The block copolypeptide with the shortest hydrophobic PBLG block, and therefore the highest hydrophilic weight fraction, $(f=76 \%)$, was first self-assembled by direct solubilization in ultrapure water at $1 \mathrm{mg} \cdot \mathrm{mL}^{-1}$ at room temperature. DLS measurements showed a monomodal size distribution, with a hydrodynamic radius $\left(\mathrm{R}_{\mathrm{h}}\right)$ of $39 \mathrm{~nm}$ and relatively low polydispersity index (PDI) of 0.13 (Figure S2a) that is consistent with the formation of spherical nanoparticles. TEM micrographs revealed the presence of a highly homogeneous dispersion of spherical nanoparticles (Figure S2b) with a rather strong intrinsic contrast certainly due to the high electron density of the benzyl group of the hydrophobic PBLG block. It is worth mentioning that $\mathrm{PBLG}_{25}-b$-ELP has the largest hydrophilic weight fraction of the whole series of copolypeptides; it is therefore supposed to have the highest critical aggregation concentration (CAC). The CAC of $\mathrm{PBLG}_{25}-b-$ 
Author manuscript of Org. Biomol. Chem., 2017,15, 10095-10104 DOI: $\underline{10.1039 / C 7 O B 01945 A}$

ELP was determined at $0.22 \mathrm{mg} \cdot \mathrm{mL}^{-1}$. Self-assembly of all copolypeptides was therefore studied at concentrations above the CAC.

Self-assembly of PBLG $_{25}$-b-ELP $(f=76 \%)$ was triggered either by dialysis or microfluidics. leading to micellar morphology, irrespective of the technique used (Figure 3). Due to the use of DMSO as organic solvent to solubilize the diblock copolypeptides, the intrinsic $\alpha$-helix conformation of the PBLG block was lost in favor of the coil conformation. ${ }^{48}$ The $\alpha$-helix conformation is however most likely reformed during the self-assembly process, as evidenced by circular dichroism (data not shown), ensuring the stability of the final structures. ${ }^{31}$ The suspension obtained by dialysis was heterogeneous as evidenced by the TEM micrograph (Figure 3a) as well as the DLS profile (Figure S3a) showing two distinct populations of particles: one most likely corresponding to individual nanoparticles with a $\mathrm{R}_{\mathrm{h}}$ of $27 \mathrm{~nm}$ and one around $100 \mathrm{~nm}$ in diameter most likely corresponding to aggregates. Self-assembly from an organic solution in DMSO in which the copolypeptide is well solubilized thus leads to the formation of smaller spherical micelles than a direct solubilization of the copolypeptide in water. The microfluidic technique proved more efficient in producing nanoparticles of homogeneous size at a ratio of 70:30 DMSO/ $\mathrm{H}_{2} \mathrm{O}$. The DLS intensity profile indeed showed a monomodal size distribution centered on $\mathrm{R}_{\mathrm{h}}=15 \mathrm{~nm}$ with a narrow polydispersity $(\mathrm{PDI}=0.14)($ Figure $\mathrm{S} 3 \mathrm{~b})$.

The hybrid block copolypeptide with a $63 \%$ hydrophilic weight fraction, namely PBLG $_{45}-b$-ELP, self-assembled similarly and formed spherical nanoparticles both by dialysis and microfluidics (Figure 3). The microfluidic technique allowed the formation of nanoparticle of homogeneous size at $\mathrm{R}_{\mathrm{h}}=17 \mathrm{~nm}(\mathrm{PDI}=0.08)$, while dialysis resulted in a more heterogeneous dispersion $\left(\mathrm{R}_{\mathrm{h}}=\right.$ $30 \mathrm{~nm}, \mathrm{PDI}=0.25$ ). (Figure S3, panels c and d, respectively). 
Author manuscript of Org. Biomol. Chem., 2017,15, 10095-10104 DOI: 10.1039/C7OB01945A

The micellar morphology observed with $\mathrm{PBLG}_{25}-b$-ELP and $\mathrm{PBLG}_{45}-b$-ELP is consistent with previous studies performed on amphiphilic diblock copolymers based on PBLG. In particular, poly(ethylene oxide)- $b$-PBLG ${ }^{49}$ (from $21 \%$ to $85 \% f$ values) as well as polysarcosine- $b$-PBLG ${ }^{50}$ ( $f=90 \%$ ) block copolymers self-assembled into spherical nanoparticles by dialysis of an organic solution against water or solvent displacement method. We also evidenced that, for these two copolypeptides with short hydrophobic PBLG chains and $f$ above $60 \%$, microfluidics provided homogeneous solvents mixing resulting in monodisperse and smaller micelles as compared to the dialysis method.

The self-assembly technique showed however to have a greater impact in the case of larger hydrophobic PBLG block. Dialysis against water of PBLG $_{95}-b$-ELP $(f=45 \%)$ led to the formation of polydisperse inter-connected worm-like micelles as shown by the TEM micrographs. (Figure 3, panel e) This observation explained the large distribution obtained by DLS with $\mathrm{R}_{\mathrm{h}}$ around $130 \mathrm{~nm}$ and high polydispersity $(\mathrm{PDI}=0.32$ ). (Figure $\mathrm{S} 3$, panel e).

Because the water content plays a very important role in the self-assembly, decreasing the solvent quality for the PBLG block firstly solubilized in DMSO and changing the chain mobility, in this part, we describe the formation of the copolymer self-assemblies depending on the $\mathrm{DMSO} / \mathrm{H}_{2} \mathrm{O}$ ratio precisely controlled by the microfluidic device.

Using a total flow rate of $100 \mu \mathrm{L} \cdot \mathrm{min}^{-1}$ and $\mathrm{DMSO} / \mathrm{H}_{2} \mathrm{O}$ ratio of $70: 30, \mathrm{PBLG}_{95}-b$-ELP formed inter-connected worm-like micelles, similar to that obtained by dialysis, as shown on Figure $3 \mathrm{f}$. Indeed, the DMSO content being rather large after microfluidic, the system is still dynamic and able to re-organize during the dialysis step, a situation similar to that resulting from the slow 
Author manuscript of Org. Biomol. Chem., 2017,15, 10095-10104 DOI: 10.1039/C7OB01945A

solvent mixing process. This observation is consistent with previous results reported for different amphiphilic copolymer systems within a similar range of hydrophilic fraction. ${ }^{51-53}$

When reducing the relative amount of DMSO in $\mathrm{H}_{2} \mathrm{O}(30: 70)$ and thus increasing the amount of selective solvent, slightly distorded micelles were observed on Figure 3g. We assumed these structures to be metastable morphologies kinetically trapped during the experimental time scale, due to the faster diffusion of water in DMSO and high hydrophobicity and rigidity of the PBLG segment. This observation confirmed previous findings that nanoparticle morphology can be controlled not solely by the thermodynamic rules, related to the macromolecular parameters (the degree of repulsion between the blocks, the lengths of the block and consequently the hydrophilic weight fraction) but also by inducing self-assembly with different techniques ${ }^{32}$ or by varying the ratio between the organic solvent and the selective solvent allowing the self-assembly via kinetic control. $^{54,55}$ Indeed, if the water content is too high, reducing drastically the solubility and chain mobility, the kinetic process of polymer self-assembly and structural rearrangement of the aggregates can be too slow to establish a dynamic equilibrium.

We finally studied the last copolypeptide of the series, namely $\mathrm{PBLG}_{180}-b$-ELP, having the lowest hydrophilic weight fraction $(f=30 \%)$. In this case, the process proved critical on the selfassembled morphologies observed. Dialysis against water of a solution of $\mathrm{PBLG}_{180}-b$-ELP led to relatively polydisperse (PDI $=0.28)$ spherical particles of $R_{h}=59 \mathrm{~nm}$ (Figures $3 \mathrm{~h}$ and S3g). Spherical micelles were also reported as stable self-assembled structures of PBLG- $b$-PEG diblock copolymers with similar hydrophilic fractions and via a similar dialysis method. ${ }^{49}$ The use of microfluidics (DMSO: $\mathrm{H}_{2} \mathrm{O}$ ratio of 70:30) however allowed the formation of vesicles as 
Author manuscript of Org. Biomol. Chem., 2017,15, 10095-10104 DOI: 10.1039/C7OB01945A

evidenced by TEM and cryo-TEM (Figure $3 i$ ). DLS measurements provided an average $R_{h}=76$ $\mathrm{nm}$ and PDI $=0.19$ (Figure S3h). The size of vesicles as measured on TEM micrographs $(\mathrm{n}=$ 150) appeared slighty smaller with an average radius of $61 \mathrm{~nm}$, this difference being attributed to the hydration sphere of the ELP segment in solution. These results mainly highlight the major advantage of the microfluidic device in controlling the formation of monodisperse nanoparticles in a metastable morphology and in highly reproducible manner. With microfluidics, the proportion of selective solvent (i.e., water) in the organic phase containing the soluble copolypeptides is directly related to the solvent mixing rate and thus the flow rate of the streams directly controls the formation of spherical or worm-like micelles or polymersomes. ${ }^{56}$

When the kinetic of self-assembly is slowed down by a highly selective solvent (here the water) and no free self-assembly is possible, the formation of polymersomes need significantly more time than the formation of spherical micelles. The vesicular structures obtained can be explained by the slower and homogenous mixing of DMSO and water in the micro-mixer, allowing the selforganization of the rigid and hydrophobic PBLG block to form the thin membrane.

\section{Conclusion}

A recombinant elastin-like polypeptides (ELPs) with a precise sequence $\mathrm{MW}\left[(\mathrm{VPGVG})(\mathrm{VPGMG})(\mathrm{VPGVG})_{2}\right]_{10}$ and named ELP-M-40 was efficiently used as macroinitiator for the ROP of the $\gamma$-benzyl- $L$-glutamate $N$-carboxyanhydride. The controlled ammonium-mediated ROP mechanism allowed us to afford library of define hybrid recombinant/synthetic diblock polypeptides with varying hydrophilic weight fractions $(f)$ : 
Author manuscript of Org. Biomol. Chem., 2017,15, 10095-10104 DOI: 10.1039/C7OB01945A

$\mathrm{PBLG}_{25}-b$-ELP $(f=76 \%), \mathrm{PBLG}_{45}-b$-ELP $(f=63 \%), \mathrm{PBLG}_{95}-b-\mathrm{ELP}(f=45 \%)$ and $\mathrm{PBLG}_{180}-b-$ $\operatorname{ELP}(f=30 \%)$ with a dispersity below 1.04 .

Thereafter, the self-assembly of this series of giant amphiphiles in water was studied using several methods: dialysis, microfluidics and direct solubilization only for $\mathrm{PBLG}_{25}-b$-ELP $(f=76$ $\%$ ). This study allows to explore the thermodynamic and kinetic conditions the most suitable for the system to obtain stable nanoparticles of controlled size and shape.

Depending on the diblock copolypeptide composition and the self-assembly protocol, the morphology of the structures formed could be controlled, ranging from micelles, worm like micelles to polymersomes and the results highlighted the advantages of using a microfluidic device to obtain more monodisperse structures of nano-objects of interest in a reproducible manner.

Overall, this contribution provides the first example of nano-assemblies of hybrid diblock based on recombinant ELPs and synthetic polypeptides. Due to their intrinsic biocompatibility, these new nanomaterials can potentially serve as platforms for the development of original nanovectors.

\section{Experimental section}

\section{Materials}

All chemicals were purchased from Sigma-Aldrich and used as received. $\gamma$-benzyl- $L$-glutamate $N$-carboxyanhydride ( $\gamma$-BLG NCA) was purchased from Isochem.

NMR spectroscopy 
Author manuscript of Org. Biomol. Chem., 2017,15, 10095-10104 DOI: 10.1039/C7OB01945A

${ }^{1} \mathrm{H}$ NMR experiments were performed in $\mathrm{CDCl}_{3}$ (with $15 \%$ of TFA) at $25{ }^{\circ} \mathrm{C}$ on a Bruker Avance I NMR spectrometer operating at $400 \mathrm{MHz}$, and equipped with a Bruker multinuclear zgradient direct probe head capable of producing gradients in the $\mathrm{z}$ direction with $53.5 \mathrm{G} . \mathrm{cm}^{-1}$ strength. ${ }^{1} \mathrm{H}$ NMR spectra were recorded with a D1 of $2 \mathrm{sec}$ and 64 scans.

\section{Size exclusion chromatography}

The molar masses and the dispersities of poly( $\gamma$-benzyl-L-glutamate)-block-ELP and the ELP precursor were determined by size exclusion chromatography (SEC) on a PL GPC50 integrated system from Agilent equipped with two KD-804 Shodex gel columns $(300 \times 8 \mathrm{~mm})$ (exclusion limits from $4000 \mathrm{Da}$ to $200000 \mathrm{Da}$ ). The detector used is a refractive index detector (Jasco 1530$\mathrm{RI})$, dimethylformamide (DMF) has been used as eluent $\left(0.8 \mathrm{~mL} \cdot \mathrm{min}^{-1}\right)$ at $50{ }^{\circ} \mathrm{C}$ in the presence of $\operatorname{LiBr}\left(1 \mathrm{~g} \cdot \mathrm{L}^{-1}\right)$.

\section{Dynamic Light Scattering}

To determine the hydrodynamic radius $\left(\mathrm{R}_{\mathrm{h}}\right)$ and the polydispersity index (PDI, a dimensionless measure of the broadness of the size distribution), single-angle light scattering analysis was achieved with an ALV laser goniometer, with a $22 \mathrm{~mW}$ linearly polarized laser (632.8 $\mathrm{nm} \mathrm{HeNe})$ and an ALV- 5000/EPP multiple tau digital correlator (125 ns initial sampling time). All the measurements were performed at a constant temperature of $25^{\circ} \mathrm{C}$ and with an angle of $90^{\circ}$. The solutions were placed in $10 \mathrm{~mm}$ diameter glass cells. Data were acquired with ALV correlator control software, and the counting time was fixed for each sample at $10 \mathrm{~s}$. The concentration of the solutions was $1 \mathrm{mg} \cdot \mathrm{mL}^{-1}$. The autocorrelation functions $\left(\mathrm{g}_{1}(\mathrm{t})\right)$ were analyzed in terms of relaxation time distribution $(\tau)$ (equation 1$)$.

$$
\mathrm{g}_{1}(\mathrm{t})=\int A_{(\tau)} \exp \left(\frac{-t}{\tau}\right) d \tau
$$

equation 1 
Author manuscript of Org. Biomol. Chem., 2017,15, 10095-10104 DOI: 10.1039/C7OB01945A

Hydrodynamic radius $\left(\mathrm{R}_{\mathrm{h}}\right)$ was determined from the Stokes-Einstein relation (equation 2).

$$
\mathrm{R}_{\mathrm{h}}=\frac{k_{B} T}{6 \pi \eta_{s} D_{0}}
$$

equation 2

Where $D_{0}$ is diffusion coefficient, $\eta_{s}$ ids the viscosity of the solvent, $T$ is absolute temperature and $\mathrm{k}_{\mathrm{B}}$ the Boltzmann constant.

For the suspension in a DMSO/water mixture (before dialysis) the hydrodynamic radius and the polydispersity index (PDI) were determined by DLS with a Zetasizer Nano ZS from Malvern Instruments operating with a $\mathrm{He}-\mathrm{Ne}$ laser source (wavelength $633 \mathrm{~nm}$, scattering angle $90^{\circ}$ ). The correlation functions were analyzed using the cumulants method.

Transmission Electron Microscopy (TEM) micrographs of polymer nanoparticles (NPs) were recorded on a Hitachi $\mathrm{H} 7650$ microscope working at $80 \mathrm{kV}$ equipped with a GATAN Orius 10.5 Megapixel camera (Bordeaux Imaging Center, Bordeaux, France).A drop of NPs dispersion was deposited on an Agar Scientific Formvar/Carbon film grid (200 mesh) without staining and the excess was removed after $1 \mathrm{~min}$.

Cryo-Transmission Electron Microscopy (cryo-TEM) micrographs were obtained as following. A drop of suspension was deposited on “quantifoil”’ (Quantifoil Micro Tools GmbH, Germany) carbon membrane. The excess of liquid on the membrane was absorbed with a filter paper and the membrane was quench-frozen quickly in liquid ethane to form a thin vitreous ice film including NPs in the holes of the grid. Once placed in a Gatan 626 cryo-holder cooled with liquid nitrogen, the samples were transferred in the microscope and observed at low temperature $\left(-180{ }^{\circ} \mathrm{C}\right)$. CryoTEM images were recorded on ultrascan 2k CCD camera (Gatan, USA), using a LaB6 JEOL 2100 (JEOL, Japan) cryo microscope operating at $200 \mathrm{kV}$ with a JEOL low dose system (Minimum Dose System, MDS) to protect the thin ice film from any irradiation before imaging and reduce the irradiation during the image capture. 
Author manuscript of Org. Biomol. Chem., 2017,15, 10095-10104 DOI: 10.1039/C7OB01945A

The critical aggregation concentration (CAC) was determined by fluorimetric method: Nile red (0.94 mg, $3.0 \mu \mathrm{mol}$ ) was dissolved in $9 \mathrm{~mL}$ of $\mathrm{CH}_{2} \mathrm{Cl}_{2}$ and $0.1 \mathrm{~mL}$ of this solution was added to a series of vials. The $\mathrm{CH}_{2} \mathrm{Cl}_{2}$ was removed under a stream of nitrogen. A series of concentrations of the nano-objects suspension ranging from to $2 \mathrm{mg} \cdot \mathrm{L}^{-1}$ to $1000 \mathrm{mg} \cdot \mathrm{L}^{-1}$ was prepared by serial twofold dilutions. The suspensions were added to the vials containing Nile red and were allowed to equilibrate with stirring overnight. The fluorescence spectra were obtained on a Varian Cary Eclipse fluorescence spectrometer from Agilent Technologies. An excitation wavelength of 550 $\mathrm{nm}$ was used for Nile red and the emission spectra were recorded from 565 to $700 \mathrm{~nm}$. The emission intensity at maximum of excitation was recorded for each concentration.

\section{Design of encoding gene, bioproduction, purification and isolation of recombinant ELP-M-40}

ELPs with high molecular weight have been efficiently produced in a large scale using Escherichia Coli as expression system. The ELP-M-40 was obtained as previously reported. ${ }^{14}$ The amino acid sequence is: $\mathrm{MW}\left[(\mathrm{VPGVG})(\mathrm{VPGMG})(\mathrm{VPGVG})_{2}\right]_{10}$ so the molecular weight is precisely 17,035 g.mol ${ }^{-1}$. The ${ }^{1} \mathrm{H}$ NMR spectrum in $\mathrm{CDCl}_{3}$ is shown in the supporting information (Figure S1).

Synthesis of block copolymers poly(y-benzyl-L-glutamate)-block-ELP

Diblock copolypeptides poly( $\gamma$-benzyl-L-glutamate)-block-ELP were synthesized by ring opening polymerization (ROP) of $\gamma$-BLG NCA using ELP as macroinitiator. Various [monomers]/[initiator] molar ratios were used to obtain copolypeptides with different hydrophilic weight fractions $f$. For example, to prepare PBLG $_{25}-b$-ELP, $\gamma$-BLG NCA $\left(9.42 \times 10^{-2} \mathrm{~g}, 3.58 \times 10^{-1}\right.$ mmol) was weighed in a glovebox under pure argon, introduced in a flame-dried schlenk, and dissolved in $2 \mathrm{~mL}$ of anhydrous DMF. The solution was stirred for $10 \mathrm{~min}$, and the ELP 
Author manuscript of Org. Biomol. Chem., 2017,15, 10095-10104 DOI: 10.1039/C7OB01945A

$\left(2.44 \times 10^{-2} \mathrm{~g}, 1.43 \times 10^{-3} \mathrm{mmol}, \mathrm{M}=17,035.4 \mathrm{Da}\right)$ was added with a nitrogen purged syringe from a solution in anhydrous DMF $\left(1 \times 10^{-2}\right.$ g.mL $\mathrm{mL}^{-1}$, injected volume: $\left.24.4 \mathrm{~mL}\right)$. The mixture was stirred for one week at $5^{\circ} \mathrm{C}$ (or at $25^{\circ} \mathrm{C}$ ) precipitated in diethyl ether, and dried under vacuum to afford a white powder. Yield: $3.12 \times 10^{-1} \mathrm{~g}(97 \%)$. A copolypeptide with a molecular mass of $22.5 \times 10^{3}$ g.mol ${ }^{-1}$ (determined by ${ }^{1} \mathrm{H} \mathrm{NMR}$ ) corresponding to the targeted degree of polymerization of 25 was obtained.

Study of self-assembly behavior of poly( $\gamma$-benzyl-L-glutamate)-block-ELP

The diblock amphiphilic copolypeptides PBLG- $b$-ELP were self-assembled using various methods to compare the structure and the size of the nano-objects obtained depending on the process used.

\section{Direct solubilization}

The first method, the direct solubilization in water was used only for the copolypeptide with the highest hydrophilic weight fraction $f, \mathrm{PBLG}_{25}-b$-ELP $(f=79 \%)$. Indeed, it was not possible to self-assemble under these conditions the others copolymers due to their lower $f$ values without formation of macroscopic aggregates. Shortly, the copolypeptide was added in ultrapure water at a concentration of $1 \mathrm{mg} \cdot \mathrm{mL}^{-1}$ and the mixture was stirred overnight at room temperature.

\section{Dialysis}

The second method used, the dialysis, consists in a solution of copolymers at $4 \mathrm{~g}$. $\mathrm{L}^{-1}$ in a common solvent of both blocks (here DMSO) dialyzed against a non-solvent of the hydrophobic block of PBLG (here deionized water). The membrane used has a cut off of $15 \mathrm{KDa}$ and the water was renewed 4 times in $24 \mathrm{~h}$. During this process, water diffused into the DMSO phase, leading to 
Author manuscript of Org. Biomol. Chem., 2017,15, 10095-10104 DOI: 10.1039/C7OB01945A

aggregation of the hydrophobic chains and driving the self-assembly process of the amphiphilic block copolypeptides.

\section{Microfluidics}

The last method consists in using a microfluidics system from Dolomite ${ }^{\circledR}$. A solution of copolypeptides at 4 g. $\mathrm{L}^{-1}$ in DMSO and deionized water were mixed in a chip containing twelve steps of mixing. Two pumps under pression of nitrogen brought the solutions with a flow rate controlled by the "Mitos Flow Control Center" software from Dolomite ${ }^{\circledR}$ (Scheme S.1). This technique allowed controlling perfectly the speed of mixing depending on the ratio DMSO/water and the total flow rate. For our study, the total flow rate is $100 \mu \mathrm{L} \cdot \mathrm{min}^{-1}$, the flow rates of the solution of copolypeptides in DMSO and the water are $30 \mu \mathrm{L} \cdot \mathrm{min}^{-1}$ and $70 \mu \mathrm{L} \cdot \mathrm{min}^{-1}$ respectively (ratio DMSO: $\mathrm{H}_{2} \mathrm{O}$ of $70: 30$ ), and also $70 \mu \mathrm{L} \cdot \mathrm{min}^{-1}$ and $30 \mu \mathrm{L} \cdot \mathrm{min}^{-1}$ for the $\mathrm{PBLG}_{95}-b$-ELP $(f=$ 45\%) (ratio DMSO: $\mathrm{H}_{2} \mathrm{O}$ of 30:70). Thereafter, the DMSO was removed by dialysis (in a membrane bag with a cut off of $15 \mathrm{KDa}$ ). Except for the suspension of $\mathrm{PBLG}_{180}-b$-ELP for which the characterizations were carried out before.

\section{Acknowledgments}

The authors thank Amélie Vax for the SEC analyzes and Julien Rosselgong for general discussions. The Transmission Electron Microscopy (TEM) was performed at the Bordeaux Imaging Center, a service unit of the CNRS-INSERM and Bordeaux University, member of the national infrastructure France BioImaging; authors are grateful to Sabrina Lacomme and Mélina Petrel for the training.

\section{References}


Author manuscript of Org. Biomol. Chem., 2017,15, 10095-10104 DOI: 10.1039/C7OB01945A

(1) Pelegri-O'Day, E. M.; Lin, E.-W.; Maynard, H. D. Therapeutic protein-polymer conjugates: advancing beyond PEGylation. Journal of the American Chemical Society 2014, 136, 14323-14332.

(2) Dirks, A. T. J.; Nolte, R. J.; Cornelissen, J. J. Protein-polymer hybrid amphiphiles. Advanced Materials 2008, 20, 3953-3957.

(3) Velonia, K.; Rowan, A. E.; Nolte, R. J. Lipase polystyrene giant amphiphiles. Journal of the American Chemical Society 2002, 124, 4224-4225.

(4) Boerakker, M. J.; Hannink, J. M.; Bomans, P. H.; Frederik, P. M.; Nolte, R. J.; Meijer, E. M.; Sommerdijk, N. A. Giant amphiphiles by cofactor reconstitution. Angewandte Chemie International Edition 2002, 41, 4239-4241.

(5) Boerakker, M. J.; Botterhuis, N. E.; Bomans, P. H.; Frederik, P. M.; Meijer, E. M.; Nolte, R. J.; Sommerdijk, N. A. Aggregation behavior of giant amphiphiles prepared by cofactor reconstitution. Chemistry-A European Journal 2006, 12, 6071-6080.

(6) Le Droumaguet, B.; Velonia, K. In Situ ATRP-Mediated Hierarchical Formation of Giant Amphiphile Bionanoreactors. Angewandte Chemie 2008, 120, 6359-6362.

(7) Le Droumaguet, B.; Mantovani, G.; Haddleton, D. M.; Velonia, K. Formation of giant amphiphiles by post-functionalization of hydrophilic protein-polymer conjugates. Journal of Materials Chemistry 2007, 17, 1916-1922.

(8) Boyer, C.; Bulmus, V.; Liu, J.; Davis, T. P.; Stenzel, M. H.; Barner-Kowollik, C. Well-defined protein- polymer conjugates via in situ RAFT polymerization. Journal of the American Chemical Society 2007, 129, 7145-7154.

(9) Liu, Z.; Dong, C.; Wang, X.; Wang, H.; Li, W.; Tan, J.; Chang, J. Self-Assembled Biodegradable Protein-Polymer Vesicle as a Tumor-Targeted Nanocarrier. ACS applied materials \& interfaces 2014, 6, 2393-2400.

(10) Liu, X.; Gao, W. In Situ Growth of Self-Assembled Protein-Polymer Nanovesicles for Enhanced Intracellular Protein Delivery. ACS applied materials \& interfaces 2017.

(11) Huang, X.; Li, M.; Green, D. C.; Williams, D. S.; Patil, A. J.; Mann, S. Interfacial assembly of protein-polymer nano-conjugates into stimulus-responsive biomimetic protocells. Nature communications 2013, 4, 2239.

(12) Urry, D. W.; Trapane, T.; Prasad, K. Phase-structure transitions of the elastin polypentapeptide-water system within the framework of composition-temperature studies. Biopolymers 1985, 24, 2345-2356.

(13) Urry, D. W. Physical chemistry of biological free energy transduction as demonstrated by elastic protein-based polymers. The Journal of Physical Chemistry B 1997, 101, 11007-11028.

(14) Petitdemange, R.; Garanger, E.; Bataille, L.; Dieryck, W.; Bathany, K.; Garbay, B.; Deming, T. J.; Lecommandoux, S. Selective tuning of elastin-like polypeptide properties via methionine oxidation. Biomacromolecules 2017, 18, 544-550.

(15) Kramer, J. R.; Petitdemange, R.; Bataille, L.; Bathany, K.; Wirotius, A.-L.; Garbay, B.; Deming, T. J.; Garanger, E.; Lecommandoux, S. Quantitative Side-Chain 
Author manuscript of Org. Biomol. Chem., 2017,15, 10095-10104 DOI: 10.1039/C7OB01945A

Modifications of Methionine-Containing Elastin-Like Polypeptides as a Versatile Tool to Tune Their Properties. ACS Macro Letters 2015, 4, 1283-1286.

(16) Petitdemange, R.; Garanger, E.; Bataille, L.; Bathany, K.; Garbay, B.; Deming, T. J.; Lecommandoux, S. Tuning Thermoresponsive Properties of Cationic Elastin-like Polypeptides by Varying Counterions and Side-Chains. Bioconjugate chemistry 2017, 28, 1403-1412.

(17) Ayres, L.; Vos, M. R.; Adams, P. H. M.; Shklyarevskiy, I. O.; van Hest, J. C. Elastin-based side-chain polymers synthesized by ATRP. Macromolecules 2003, 36, 5967-5973.

(18) Ayres, L.; Koch, K.; Adams, P. H. H.; van Hest, J. C. Stimulus responsive behavior of elastin-based side chain polymers. Macromolecules 2005, 38, 1699-1704.

(19) Roberts, S. K.; Chilkoti, A.; Setton, L. A. Multifunctional thermally transitioning oligopeptides prepared by ring-opening metathesis polymerization. Biomacromolecules 2007, 8 , 2618-2621.

(20) Conrad, R. M.; Grubbs, R. H. Tunable, Temperature-Responsive Polynorbornenes with Side Chains Based on an Elastin Peptide Sequence. Angewandte Chemie International Edition 2009, 48, 8328-8330.

(21) Kojima, C.; Irie, K. Synthesis of Temperature-Dependent Elastin-Like PeptideModified Dendrimer for Drug Delivery. Biopolymers 2013, 100, 714-721.

(22) Luo, T.; Kiick, K. L. Noncovalent Modulation of the Inverse Temperature Transition and Self-Assembly of Elastin-b-Collagen-like Peptide Bioconjugates. Journal of the American Chemical Society 2015, 137, 15362-15365.

(23) Pu, Y.; Zhang, L.; Zheng, H.; He, B.; Gu, Z. Synthesis and Drug Release of StarShaped Poly (benzyl L-aspartate)-block-poly (ethylene glycol) Copolymers with POSS Cores. Macromolecular bioscience 2014, 14, 289-297.

(24) Shen, J.; Chen, C.; Fu, W.; Shi, L.; Li, Z. Conformation-specific self-assembly of thermo-responsive poly (ethylene glycol)-b-polypeptide diblock copolymer. Langmuir 2013, 29, 6271-6278.

(25) Lee, H.; Park, J. B.; Chang, J. Y. Synthesis of poly (ethylene glycol)/polypeptide/poly (D, L-lactide) copolymers and their nanoparticles. Journal of Polymer Science Part A: Polymer Chemistry 2011, 49, 2859-2865.

(26) Gao, H.; Hu, Z.; Guan, Q.; Liu, Y.; Zhu, F.; Wu, Q. Synthesis and thermoreversible gelation of coil-helical polyethylene-block-poly ( $\gamma$-benzyl-L-glutamate) diblock copolymer. Polymer 2013, 54, 4923-4929.

(27) Holley, A. C.; Ray, J. G.; Wan, W.; Savin, D. A.; McCormick, C. L. Endolytic, pH-responsive HPMA-b-(1-Glu) copolymers synthesized via sequential aqueous RAFT and ringopening polymerizations. Biomacromolecules 2013, 14, 3793-3799.

(28) Waley, S.; Watson, J. In Tilte1949; The Royal Society.

(29) Ballard, D.; Bamford, C. 77. Reactions of N-carboxy- $\alpha$-amino-acid anhydrides catalysed by tertiary bases. Journal of the Chemical Society (Resumed) 1956, 381-387. 
Author manuscript of Org. Biomol. Chem., 2017,15, 10095-10104 DOI: 10.1039/C7OB01945A

(30) Rodríguez-Hernández, J.; Lecommandoux, S. Reversible inside-out micellization of $\mathrm{pH}$-responsive and water-soluble vesicles based on polypeptide diblock copolymers. Journal of the American Chemical Society 2005, 127, 2026-2027.

(31) Holowka, E. P.; Pochan, D. J.; Deming, T. J. Charged polypeptide vesicles with controllable diameter. Journal of the American Chemical Society 2005, 127, 12423-12428.

(32) Huang, J.; Bonduelle, C.; Thévenot, J.; Lecommandoux, S. b.; Heise, A. Biologically active polymersomes from amphiphilic glycopeptides. Journal of the American Chemical Society 2011, 134, 119-122.

(33) Upadhyay, K. K.; Meins, J.-F. L.; Misra, A.; Voisin, P.; Bouchaud, V.; Ibarboure, E.; Schatz, C.; Lecommandoux, S. Biomimetic doxorubicin loaded polymersomes from hyaluronan-block-poly ( $\gamma$-benzyl glutamate) copolymers. Biomacromolecules 2009, 10, 2802 2808.

(34) Schatz, C.; Louguet, S.; Le Meins, J. F.; Lecommandoux, S. Polysaccharideblock-polypeptide Copolymer Vesicles: Towards Synthetic Viral Capsids. Angewandte Chemie International Edition 2009, 48, 2572-2575.

(35) Upadhyay, K. K.; Bhatt, A. N.; Mishra, A. K.; Dwarakanath, B. S.; Jain, S.; Schatz, C.; Le Meins, J.-F.; Farooque, A.; Chandraiah, G.; Jain, A. K. The intracellular drug delivery and anti tumor activity of doxorubicin loaded poly ( $\gamma$-benzyl l-glutamate)-b-hyaluronan polymersomes. Biomaterials 2010, 31, 2882-2892.

(36) Hadjichristidis, N.; Iatrou, H.; Pitsikalis, M.; Sakellariou, G. Synthesis of welldefined polypeptide-based materials via the ring-opening polymerization of $\alpha$-amino acid $\mathrm{N}$ carboxyanhydrides. Chemical reviews 2009, 109, 5528-5578.

(37) Cheng, J.; Deming, T. J.: Synthesis of polypeptides by ring-opening polymerization of $\alpha$-amino acid N-carboxyanhydrides. In Peptide-based materials; Springer, 2011; pp 1-26.

(38) Huang, J.; Heise, A. Stimuli responsive synthetic polypeptides derived from Ncarboxyanhydride (NCA) polymerisation. Chemical Society Reviews 2013, 42, 7373-7390.

(39) Habraken, G. J.; Peeters, M.; Dietz, C. H.; Koning, C. E.; Heise, A. How controlled and versatile is N-carboxy anhydride (NCA) polymerization at 0 C? Effect of temperature on homo-, block-and graft (co) polymerization. Polymer Chemistry 2010, 1, 514524.

(40) Hanby, W.; Waley, S.; Watson, J. 632. Synthetic polypeptides. Part II. Polyglutamic acid. Journal of the Chemical Society (Resumed) 1950, 3239-3249.

(41) Vayaboury, W.; Giani, O.; Cottet, H.; Deratani, A.; Schué, F. Living Polymerization of $\alpha$-Amino Acid N-Carboxyanhydrides (NCA) upon Decreasing the Reaction Temperature. Macromolecular rapid communications 2004, 25, 1221-1224.

(42) Habraken, G. J.; Wilsens, K. H.; Koning, C. E.; Heise, A. Optimization of Ncarboxyanhydride (NCA) polymerization by variation of reaction temperature and pressure. Polymer Chemistry 2011, 2, 1322-1330. 
Author manuscript of Org. Biomol. Chem., 2017,15, 10095-10104 DOI: 10.1039/C7OB01945A

(43) Lu, H.; Wang, J.; Song, Z.; Yin, L.; Zhang, Y.; Tang, H.; Tu, C.; Lin, Y.; Cheng, J. Recent advances in amino acid N-carboxyanhydrides and synthetic polypeptides: chemistry, self-assembly and biological applications. Chemical Communications 2014, 50, 139-155.

(44) Nakamura, R.; Aoi, K.; Okada, M. Controlled Synthesis of a Chitosan-Based Graft Copolymer Having Polysarcosine Side Chains Using the NCA Method with a Carboxylic Acid Additive. Macromolecular rapid communications 2006, 27, 1725-1732.

(45) Chécot, F.; Brûlet, A.; Oberdisse, J.; Gnanou, Y.; Mondain-Monval, O.; Lecommandoux, S. Structure of polypeptide-based diblock copolymers in solution: Stimuliresponsive vesicles and micelles. Langmuir 2005, 21, 4308-4315.

(46) Peyret, A.; Trant, J. F.; Bonduelle, C. V.; Ferji, K.; Jain, N.; Lecommandoux, S.; Gillies, E. R. Synthetic glycopolypeptides: synthesis and self-assembly of poly ( $\gamma$-benzyl-Lglutamate)-glycosylated dendron hybrids. Polymer Chemistry 2015, 6, 7902-7912.

(47) Bonduelle, C.; Huang, J.; Ibarboure, E.; Heise, A.; Lecommandoux, S. Synthesis and self-assembly of "tree-like" amphiphilic glycopolypeptides. Chemical communications 2012, $48,8353-8355$.

(48) Bradbury, E.; Crane-Robinson, C.; Paolillo, L.; Temussi, P. Nmr studies of the helix-coil transition of polypeptides in non-protonating solvent mixtures. Polymer 1973, 14, 303 308.

(49) Jeong, Y.-I.; Seo, S.-J.; Park, I.-K.; Lee, H.-C.; Kang, I.-C.; Akaike, T.; Cho, C.-S. Cellular recognition of paclitaxel-loaded polymeric nanoparticles composed of poly ( $\gamma$-benzyl Lglutamate) and poly (ethylene glycol) diblock copolymer endcapped with galactose moiety. International journal of pharmaceutics 2005, 296, 151-161.

(50) Heller, P.; Mohr, N.; Birke, A.; Weber, B.; Reske-Kunz, A.; Bros, M.; Barz, M. Directed Interactions of Block Copolypept (o) ides with Mannose-binding Receptors: PeptoMicelles Targeted to Cells of the Innate Immune System. Macromolecular bioscience 2015, 15, 63-73.

(51) Discher, D. E.; Eisenberg, A. Polymer vesicles. Science 2002, 297, 967-973.

(52) Lee, C.-U.; Lu, L.; Chen, J.; Garno, J. C.; Zhang, D. Crystallization-driven thermoreversible gelation of coil-crystalline cyclic and linear diblock copolypeptoids. ACS Macro Letters 2013, 2, 436-440.

(53) Kakkar, D.; Mazzaferro, S.; Thevenot, J.; Schatz, C.; Bhatt, A.; Dwarakanath, B. S.; Singh, H.; Mishra, A. K.; Lecommandoux, S. Amphiphilic PEO-b-PBLG Diblock and PBLGb-PEO-b-PBLG Triblock Copolymer Based Nanoparticles: Doxorubicin Loading and In Vitro Evaluation. Macromolecular bioscience 2015, 15, 124-137.

(54) Zhang, L.; Eisenberg, A. Thermodynamic vs kinetic aspects in the formation and morphological transitions of crew-cut aggregates produced by self-assembly of polystyrene-bpoly (acrylic acid) block copolymers in dilute solution. Macromolecules 1999, 32, 2239-2249.

(55) Cui, H.; Chen, Z.; Zhong, S.; Wooley, K. L.; Pochan, D. J. Block copolymer assembly via kinetic control. Science 2007, 317, 647-650. 
Author manuscript of Org. Biomol. Chem., 2017,15, 10095-10104 DOI: 10.1039/C7OB01945A

(56) Bleul, R.; Thiermann, R.; Maskos, M. Techniques to control polymersome size. Macromolecules 2015, 48, 7396-7409. 

Author manuscript of Org. Biomol. Chem., 2017,15, 10095-10104 DOI: 10.1039/C7OB01945A

Table 1. Molecular characteristics of ELP and of the different hybrid diblock copolypeptides PBLG- $b$-ELP obtained by ROP of $\gamma$-BLG NCA at $5{ }^{\circ} \mathrm{C}$.

\begin{tabular}{|c|c|c|c|c|c|c|c|}
\hline Copolypeptide & $\begin{array}{c}\text { Expected } \\
\text { DP } \\
\text { (PBLG) }\end{array}$ & $\begin{array}{l}\text { DP PBLG } \\
\left({ }^{1} \mathrm{H} \text { NMR) }\right.\end{array}$ & $\begin{array}{c}M_{n} \\
{ }^{1} \mathrm{H} \mathrm{NMR} \\
\left(\mathrm{g} \cdot \mathrm{mol}^{-1}\right)\end{array}$ & $f(\%)^{*}$ & $\begin{array}{c}\bar{M}_{n} \\
\mathrm{SEC}^{* *} \\
\left(\mathrm{~g} \cdot \mathrm{mol}^{-1}\right)\end{array}$ & $\stackrel{\text { D }}{\text { SEC }^{* *}}$ & $\begin{array}{c}\text { Yield } \\
(\%)\end{array}$ \\
\hline ELP & - & - & - & - & 18,000 & 1.03 & - \\
\hline PBLG $_{25}-b$-ELP & 25 & 25 & 22,500 & 76 & 33,300 & 1.02 & 97 \\
\hline PBLG $_{45}-b$-ELP & 52 & 45 & 26,900 & 63 & 40,100 & 1.02 & 85 \\
\hline PBLG $_{95}-b$-ELP & 117 & 95 & 37,800 & 45 & 49,800 & 1.03 & 88 \\
\hline PBLG $_{180}-b$-ELP & 181 & 180 & 56,500 & 30 & 56,200 & 1.03 & 93 \\
\hline
\end{tabular}

*f: hydrophilic weight fraction determined from the $\overline{M_{n}}$ calculated by ${ }^{1} \mathrm{H}$ NMR $*$ SEC in DMF $\left(0.8 \mathrm{~mL} \cdot \mathrm{min}^{-1}\right)$ at $50{ }^{\circ} \mathrm{C}$ in the presence of $\mathrm{LiBr}\left(1 \mathrm{~g} . \mathrm{L}^{-1}\right)$ with RI detector and polystyrene used as standard. 
Author manuscript of Org. Biomol. Chem., 2017,15, 10095-10104 DOI: 10.1039/C7OB01945A

Table 2. Characteristics of nanometer-sized particles obtained from the self-assembly of amphiphilic PBLG- $b$-ELP hybrid copolypeptides.

\begin{tabular}{|c|c|c|c|c|}
\hline Copolypeptide & $\begin{array}{c}f(\%) \\
{ }^{1} \text { H NMR }\end{array}$ & $\begin{array}{c}\text { Self-assembly } \\
\text { process }\end{array}$ & $\begin{array}{l}\mathbf{R}_{\mathbf{h}}{ }^{*} \\
\text { PDI }\end{array}$ & $\begin{array}{c}\text { Structure of } \\
\text { nano- } \\
\text { objects }\end{array}$ \\
\hline \multirow{3}{*}{ PBLG $_{25}-b$-ELP } & \multirow{3}{*}{76} & Dialysis & $\begin{array}{c}27 \mathrm{~nm} \\
0.32\end{array}$ & $\begin{array}{c}\text { Micelles } \\
+ \text { aggregates }\end{array}$ \\
\hline & & Microfluidics & $\begin{array}{c}15 \mathrm{~nm} \\
0.14\end{array}$ & Micelles \\
\hline & & $\begin{array}{c}\text { Direct } \\
\text { solubilization }\end{array}$ & $\begin{array}{c}39 \mathrm{~nm} \\
0.13\end{array}$ & Spheres \\
\hline \multirow{2}{*}{ PBLG $_{45}-b-E L P$} & \multirow{2}{*}{63} & Dialysis & $\begin{array}{c}30 \mathrm{~nm} \\
0.25\end{array}$ & Micelles \\
\hline & & Microfluidics & $\begin{array}{c}17 \mathrm{~nm} \\
0.08\end{array}$ & Micelles \\
\hline \multirow{3}{*}{ PBLG $_{95}-b$-ELP } & \multirow{3}{*}{45} & Dialysis & $\begin{array}{c}133 \mathrm{~nm} \\
0.32\end{array}$ & $\begin{array}{l}\text { Worm-like } \\
\text { micelles }\end{array}$ \\
\hline & & Microfluidics & $\begin{array}{c}128 \mathrm{~nm} \\
0.29\end{array}$ & $\begin{array}{c}\text { Worm-like } \\
\text { micelles }\end{array}$ \\
\hline & & Microfluidics*** & $\begin{array}{c}42 \mathrm{~nm} \\
0.47 \\
\end{array}$ & Spheres \\
\hline \multirow{2}{*}{ PBLG $_{180}-b$-ELP } & \multirow{2}{*}{30} & Dialysis & $\begin{array}{c}63 \mathrm{~nm} \\
0.28\end{array}$ & Spheres \\
\hline & & Microfluidics & $\begin{array}{c}76 \mathrm{~nm} \\
0.19\end{array}$ & Vesicles \\
\hline
\end{tabular}

* Determined by DLS at $90^{\circ}$ at $1 \mathrm{mg} \cdot \mathrm{mL}^{-1}$

**Observed by TEM

****Ratio DMSO: $\mathrm{H}_{2} \mathrm{O}$ of $30: 70$ 
Author manuscript of Org. Biomol. Chem., 2017,15, 10095-10104 DOI: 10.1039/C7OB01945A

Scheme 1. Synthesis of hybrid diblock copolymers poly( $\gamma$-benzyl- $L$-glutamate)-block-ELP by ROP of $\gamma$-BLG NCA initiated by the primary ammonium terminal group of the ELP.

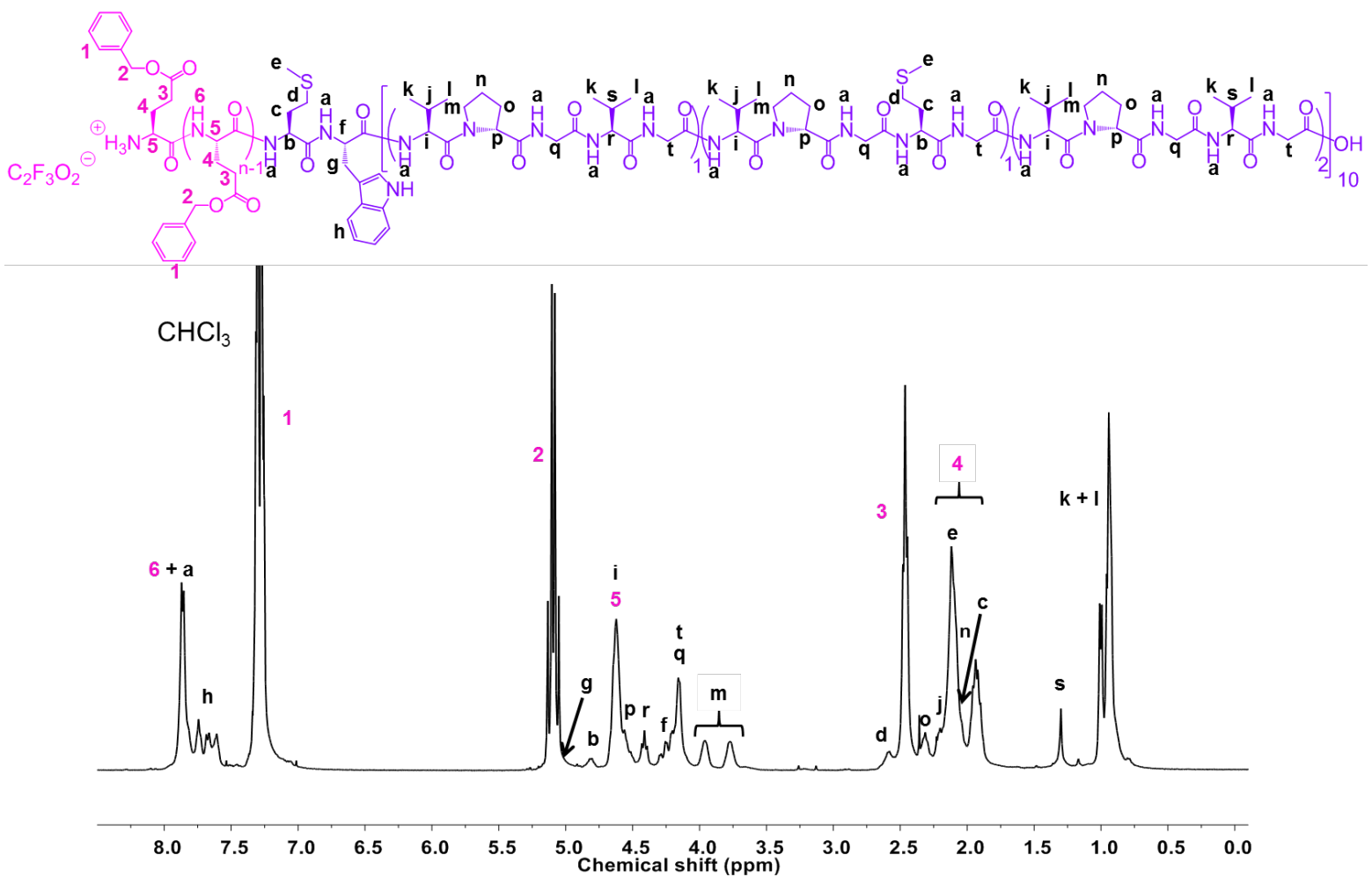

Figure 1. ${ }^{1} \mathrm{H}$ NMR spectrum of poly( $\gamma$-benzyl- $L$-glutamate $)_{180}$-block-ELP in $\mathrm{CDCl}_{3}(15 \% \mathrm{TFA})$.
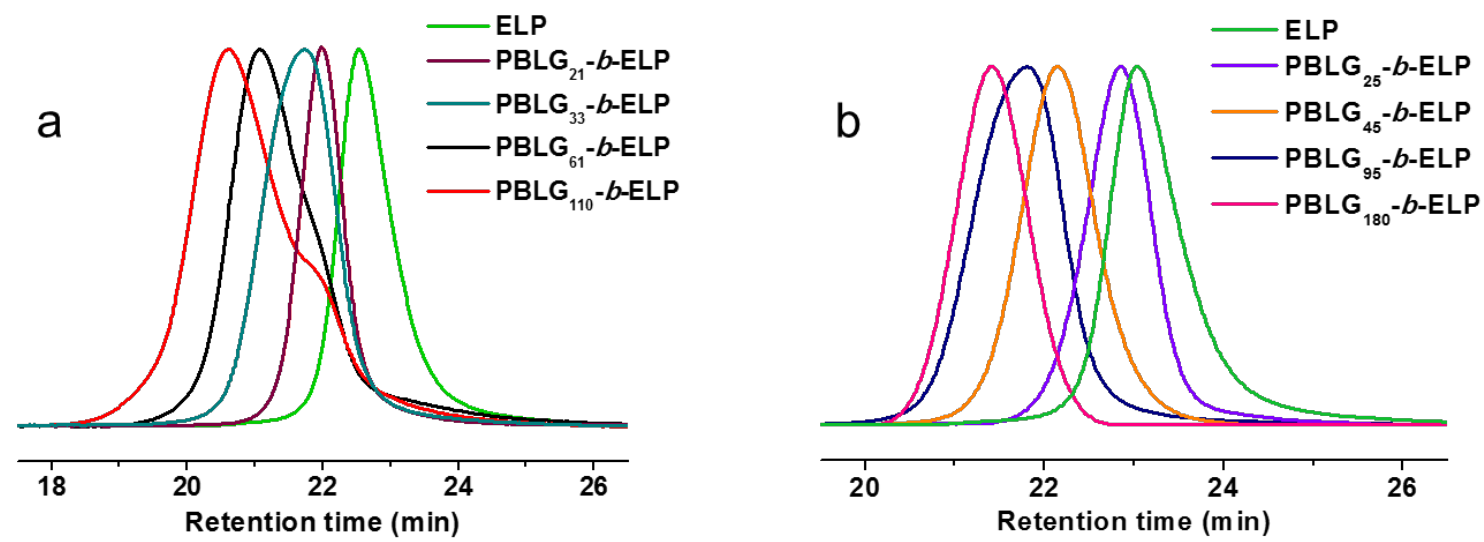

Figure 2. Size exclusion chromatography traces of ELP and hybrid diblock copolypeptides PBLG- $b$-ELP obtained by ROP of $\gamma$-BLG NCA at $25^{\circ} \mathrm{C}$ (a) and at $5{ }^{\circ} \mathrm{C}(\mathrm{b})$. 
Author manuscript of Org. Biomol. Chem., 2017,15, 10095-10104 DOI: 10.1039/C7OB01945A

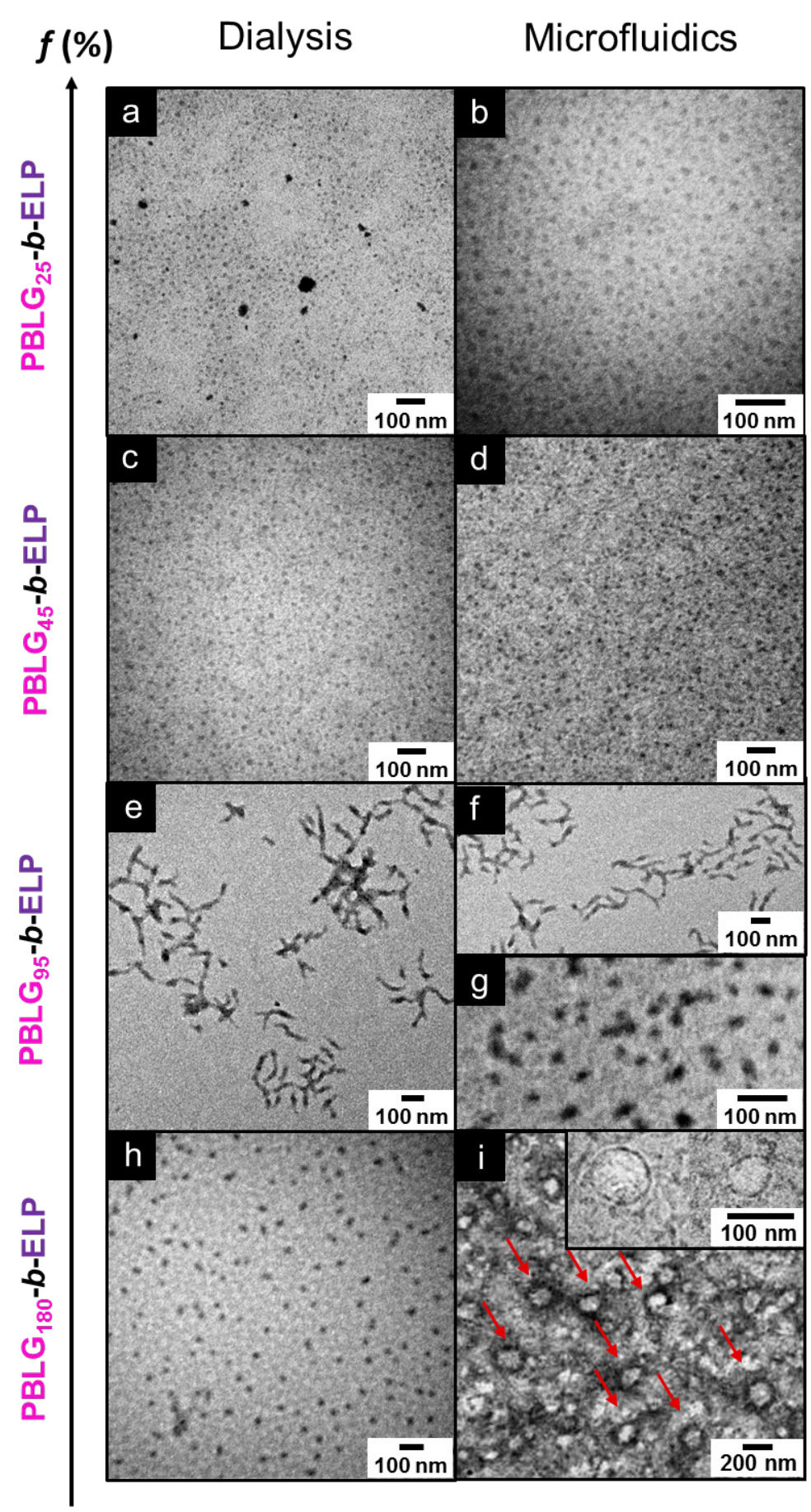

Figure 3. TEM micrographs of nano-objects obtained from $\mathrm{PBLG}_{\mathrm{n}}-b$-ELP depending on the selfassembly process. (f) Ratio DMSO: $\mathrm{H}_{2} \mathrm{O}$ by microfluidics 70:30, (g) Ratio DMSO: $\mathrm{H}_{2} \mathrm{O}$ by 
microfluidics 30:70, (i) observed directly after the formation of nano-objects (cryo-TEM in the insert).

TOC

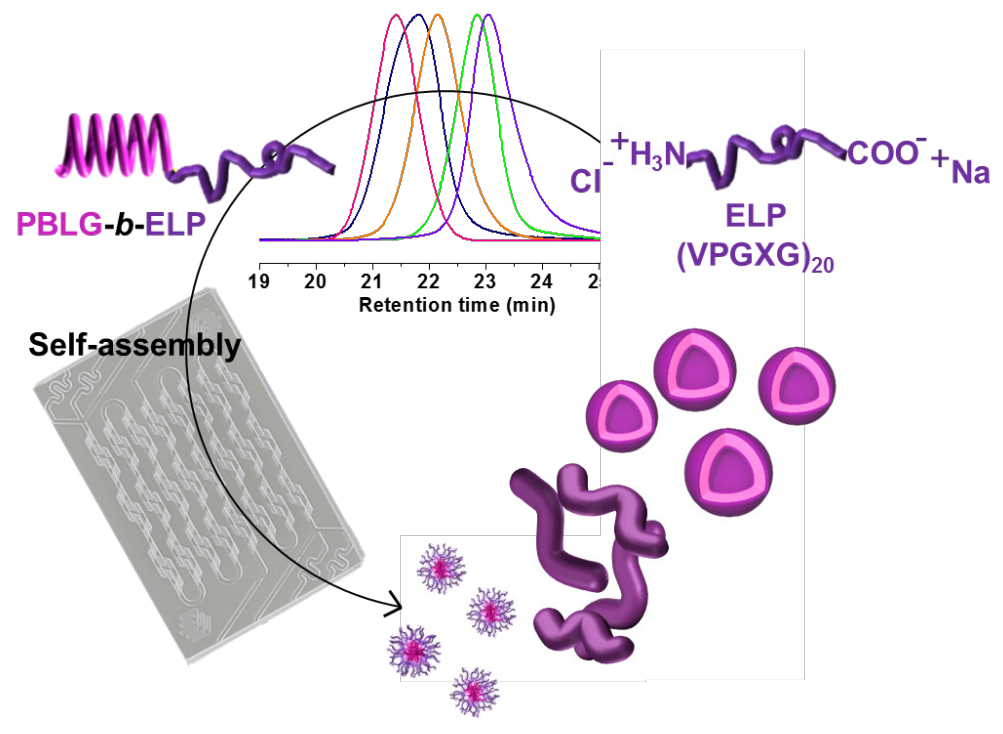


SUPPORTING INFORMATION:

\section{Design and self-assembly of PBLG-b-ELP hybrid diblock copolymers based on synthetic and elastin-like polypeptides}

Gaëlle Le Fer ${ }^{\S \dagger}$, Delphine Portes ${ }^{\S \dagger}$, Guillaume Goudounet ${ }^{\S \dagger}$, Jean-Michel Guigner ${ }^{\ddagger}$, Elisabeth Garanger $^{\S \dagger}$, Sébastien Lecommandoux ${ }^{\S \dagger^{* *}}$

§Université de Bordeaux/Bordeaux INP, ENSCBP, 16 avenue Pey-Berland, Pessac 33607, France

†CNRS, Laboratoire de Chimie des Polymères Organiques (UMR5629), Pessac, France Institut de Minéralogie et de Physique des Milieux Condensés (IMPMC) 4 place Jussieu 75005 Paris - France

\section{Synthesis mechanism hypothesis}

Because the purification of ELP involves the use of sodium chloride, we can reasonably assume the polymerization to be initiated by the $N$-terminal ammonium group of the ELP with the chloride $\mathrm{Cl}^{-}$as counter-anion. Consequently, the block copolypeptides poly $(\gamma$-benzyl- $L$ glutamate)-block-ELP were synthesized by ROP of the $\gamma$-BLG NCA initiated by the primary ammonium end group of the ELP.

It was previously postulated by Schlaad et $a l$. that the ammonium-mediated ROP mechanism may lead to a controlled propagation comparable to nitroxyde-mediated radical or living cationic polymerizations involving an equilibrium between dormant (ammonium) and active (amine) chain ends ${ }^{1}$ provided that the counter-anion, here the nucleophilic chloride anion, is quite mobile in the medium. ${ }^{1,2}$ The ammonium salt in addition is suspected to suppress the activated monomer mechanism (AMM) due to protonation of the NCA anions. ${ }^{1}$ 
Interestingly, in the present case of the polymerization of $\gamma$-BLG NCA, we suspect the ELP macroinitiator to afford sufficient polarity to the medium to allow an excellent control of ammonium-mediated ROP with the chloride counterion. We additionally presume the formation of hydrogen bonds between the polypeptide chain amide groups and the $\gamma$-BLG NCA, stabilizing the latter and limiting the AMM mechanism, and consequently favoring the normal NAM amine mechanism.

Table S1. Molecular characteristics of ELP and hybrid diblock copolypeptides PBLG- $b$-ELP obtained by ROP of $\gamma$-BLG NCA at $25^{\circ} \mathrm{C}$.

\begin{tabular}{|c|c|c|c|c|c|c|c|c|}
\hline$\#$ & Copolypeptide & $\begin{array}{c}\text { Expected DP } \\
\text { (PBLG) }\end{array}$ & $\begin{array}{l}\text { DP PBLG } \\
\left({ }^{1} \mathrm{H} \text { NMR }\right)\end{array}$ & 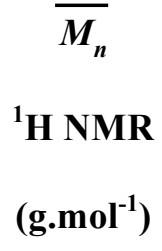 & $\begin{array}{c}f(\%) \\
{ }^{1} \text { H NMR }\end{array}$ & $\begin{array}{c}\overline{M_{n}} \\
\mathrm{SEC}^{*} \\
\left(\mathrm{~g} \cdot \mathrm{mol}^{-1}\right)\end{array}$ & $\begin{array}{c}\boldsymbol{D} \\
\text { SEC* }\end{array}$ & $\begin{array}{l}\text { Yield } \\
(\%)\end{array}$ \\
\hline- & ELP & - & - & 17,000 & - & 18,000 & 1.03 & - \\
\hline 1 & PBLG $_{21}-b$-ELP & 52 & 21 & 21,600 & 79 & 24,900 & 1.03 & 73 \\
\hline 2 & PBLG $_{33}-b-E L P$ & 78 & 33 & 24,300 & 70 & 30,200 & 1.06 & 80 \\
\hline 3 & PBLG $_{61}-b-E L P$ & 117 & 61 & 30,400 & 56 & 37,100 & 1.15 & 77 \\
\hline 4 & PBLG $_{110}-b$-ELP & 181 & 110 & 41,200 & 41 & 44,800 & 1.20 & 70 \\
\hline
\end{tabular}

*f: hydrophilic weight fraction determined from the $\bar{M}_{n}$ calculated by ${ }^{1} \mathrm{H}$ NMR

$* * \mathrm{SEC}$ in DMF $\left(0.8 \mathrm{~mL} \cdot \mathrm{min}^{-1}\right)$ at $50{ }^{\circ} \mathrm{C}$ in the presence of $\mathrm{LiBr}\left(1 \mathrm{~g} \cdot \mathrm{L}^{-1}\right)$ with $\mathrm{RI}$ detector and polystyrene used as standard. 


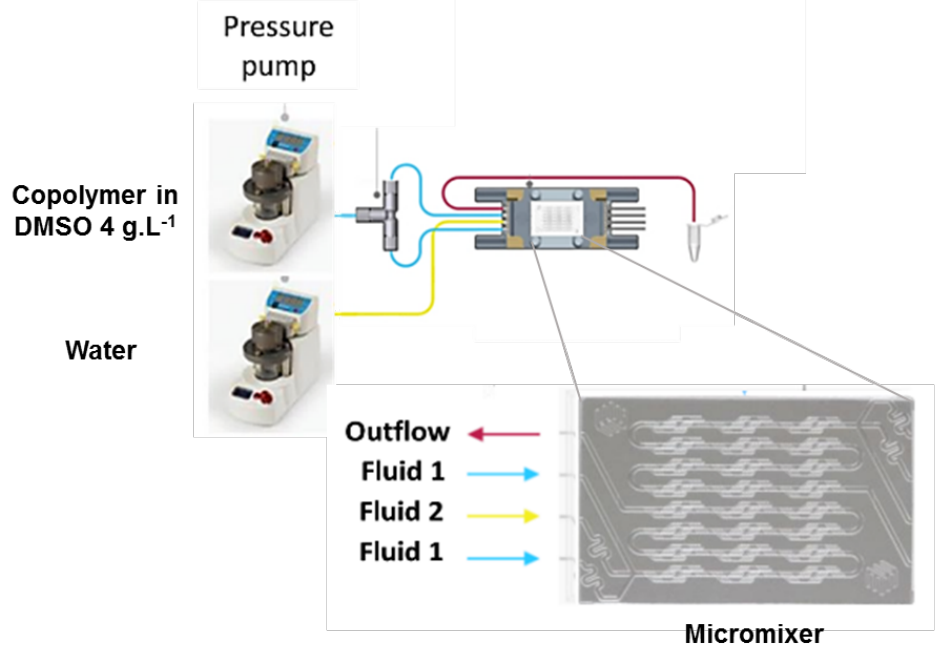

Scheme S1. Schematic representation of the microfluidics device used.
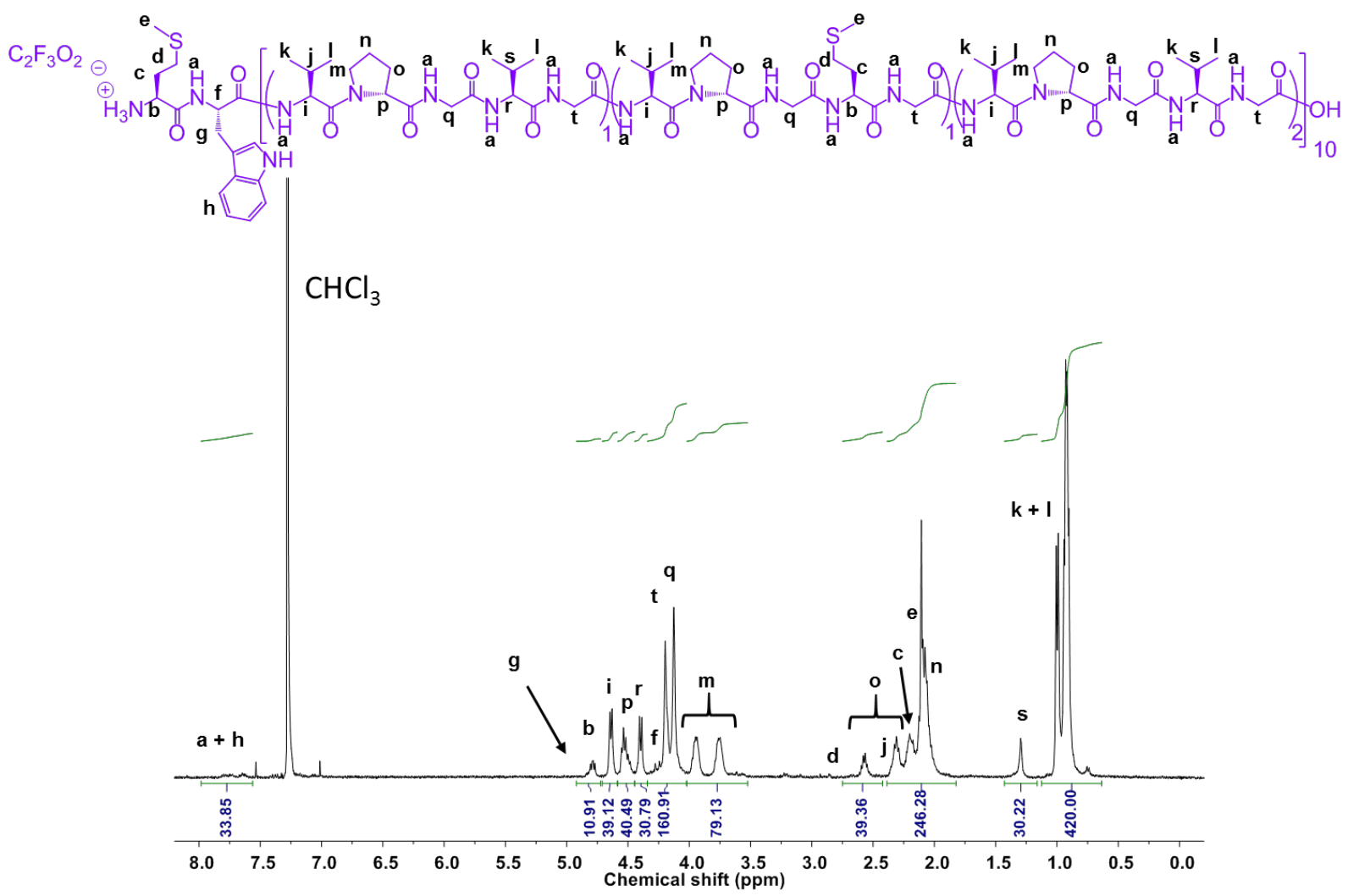

Figure S1. ${ }^{1} \mathrm{H}$ NMR spectrum of ELP in $\mathrm{CDCl}_{3}$ containing $15 \%$ trifluoroacetic acid (TFA). 

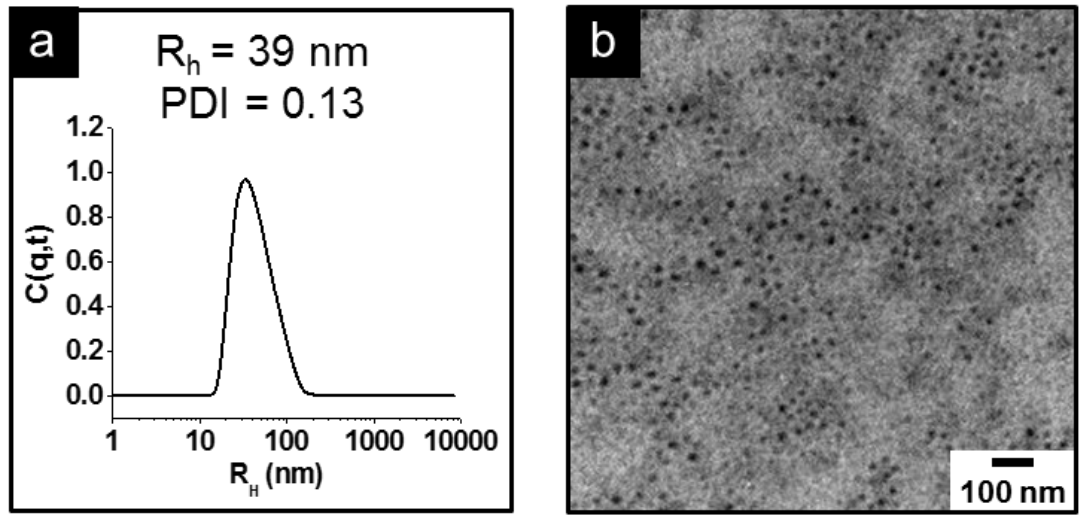

Figure S2. (a) Size distribution of nano-particles by DLS.(b) TEM micrographs of nanoparticles obtained from $\mathrm{PBLG}_{25}-b$-ELP by direct solubilization. 


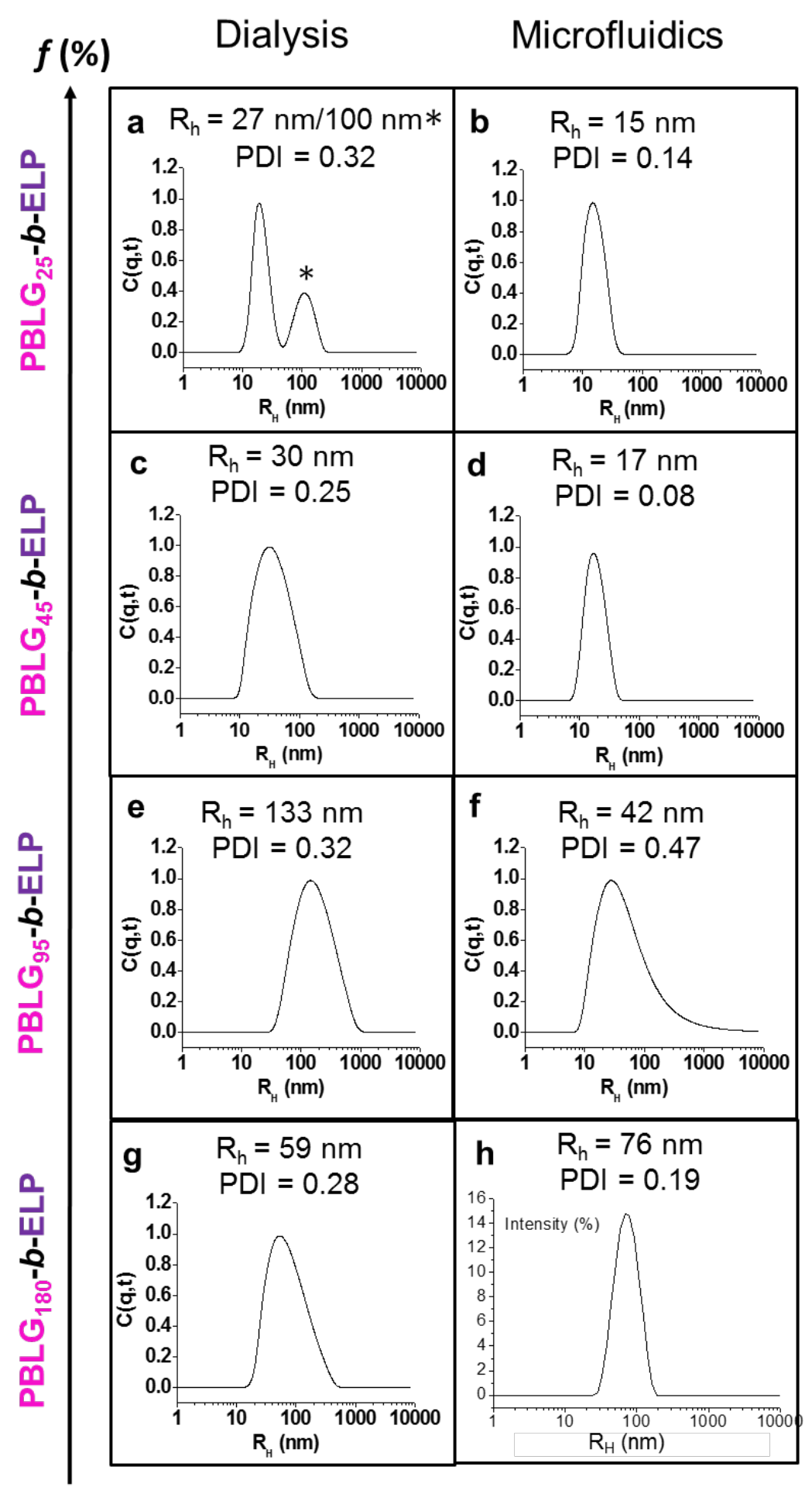

Figure S3. Size distribution of nano-particles by DLS depending on the technique of selfassembly process. (i) Characterized directly after the formation of nano-objects. Ratio DMSO: $\mathrm{H}_{2} \mathrm{O}$ by microfluidics is $70: 30$. 
(1) Dimitrov, I.; Schlaad, H. Chemical Communications 2003, 2944-2945.

(2) Lutz, J. F.; Schütt, D.; Kubowicz, S. Macromolecular rapid communications 2005, 26, 23-28. 